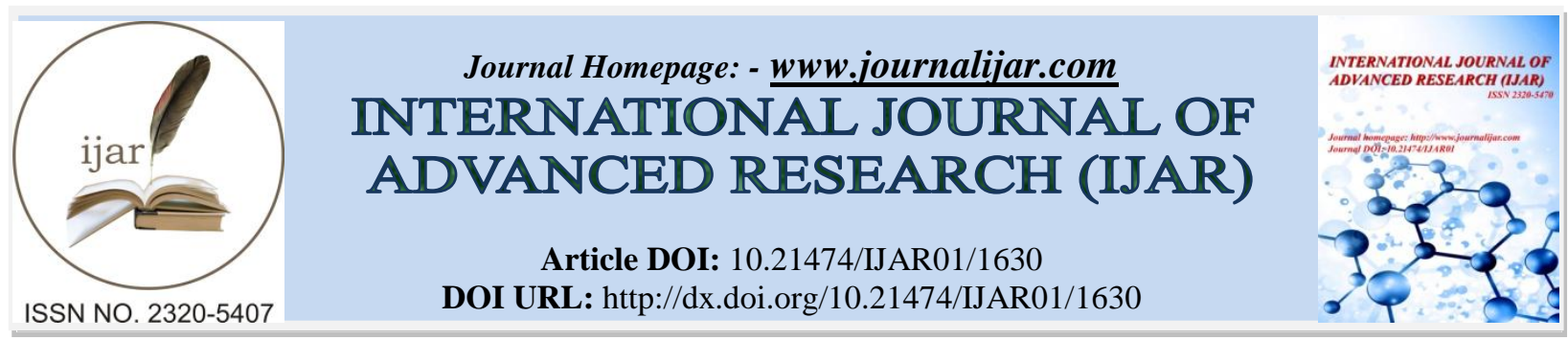

RESEARCH ARTICLE

\title{
IMPORTANCE OF LAC CULTURE ON SOCIO-ECONOMIC AND BIODIVERSITY CONSERVATION FRONTS.
}

Dr. Alkesh I. Shah.

Associate Professor \& Head, Zoology Department, B. P. Baria Science Institute, Navsari - 396445, Gujarat, India.

\section{Manuscript Info}

Manuscript History

Received: 12 July 2016

Final Accepted: 23 August 2016

Published: September 2016

Key words:-

Biodiversity, Lac insects, Lac culture,

Resin, Broodlac.

\section{Abstract}

Lac is a resin secretion of insects, which are commercially cultivated through ages. Lac cultivation has its roots in India and Bangladesh, the two main Asian countries in the world and was a major source of economy to the local populace. Natural red color obtained on purification of this resin was used in coloring of items like wood and textiles. With the advent of synthetic dyes since last 150 years, this technique was abandoned to a large extent due to its low profitability. Recent research has actually shown that Lac culture has a number of beneficial effects on the conservation of biodiversity, which is an aspect of great concern as the loss of biodiversity has put a question mark to the ultimate survival of human race on this planet. Revival and improvements of Lac culture is proposed to achieve this goal. This paper discusses the better aspects of Lac culture, as well as its effects on the biodiversity.

Copy Right, IJAR, 2016,. All rights reserved.

\section{Introduction:-}

Lac is a red colored resinous secretion of Lac insects cultivated since ages mainly in the Asian countries of India and Bangladesh, followed by Myanmar, Thailand and China and to some extent in Vietnam and Mexico. It is generally categorized as a 'Non-timber Forest Produce'3. The most species of the insects that are cultivated are Kerria lacca. The word 'Lac' has its origin in Sanskrit, meaning 'Lakh', a numerical figure 100000. This insect has been probably known by this word due to the enormously large number in which these insects are found in a small area. The resin obtained finds use as wood finish, in preparation of cosmetics, and in dyeing of natural fibers like wool and silk. India was the major exporter of Lac to the European countries of the world 5 .

Lac cultivation is done by the farmer acquiring a 'broodlac', a stick covered with eggs of the insect that are on the verge of hatching. This broodlac is tied on to the branch of a tree where the insects are intended to infest on. Lakhs of the insects grow into large colonies on the branches of the tree, and secrete the resinous product. The resin coated branches of the tree, referred to as 'Sticklac' are cut and processed to obtain Lac. These Sticklac branches are crushed and sieved to remove most of the impurities. The sieved powder is then repeatedly washed with cold water in order to obtain a purified product known as 'seedlac' due to it resembling pellet in shape. The remaining impurities in Seedlac is removed either by dissolving in solvent or by heating.

The red color of the resin comes from the insects. The insects that manifest on the wood are kept on the sticklac if the resin is ultimately used for obtaining the dye. The prevailing insects are killed by exposure to sunlight before purification. The use of Lac declined with the advent of synthetic dyes due to they being cheap and economically

Corresponding Author:- Dr. Alkesh I. Shah.

Address:- Associate Professor \& Head, Zoology Department, B. P. Baria Science Institute, Navsari - 
viable to the user. Still, Lac finds use as food additive in the manufacture of soft drinks, beverages, juices, jam, and also in folk medicine as a anti obesity and as a hepatoprotective drug ${ }^{5}$.

\section{Description of Lac Insect Species:-}

The three main cultivable species of Lac insects are:

1. Kerria lacca

2. Paratachardina decorella

3. Paratachardina pseudolobata

\section{Kerria lacca:-}

It is the most common and important species of Lac insects belonging to the family 'Kerridae' grouped in the main family 'Coccoidea', the scale insects. This species is a native of India and is of great economic value due to the superb quality of the resin produced by it, which finds application in the manufacture of 'Shellac' and other items. This insect species also secretes dye and wax which are useful sources of livelihood for the farmer. The larvae of this species start crawling on the branches of the host plant and feed on the phloem inside by piercing holes and filling up the same with their naturally secreted wax. The dye produced by these species is of dark scarlet-red color originating from the haemolymph of the insect, and is widely used in the coloration of wool and silk fibers. This species is able to grow on a large number of host plants out of which the following three plants: Ber (Ziziphus mauritiana), Kusum (Schleichera oleosa) and Palas (Butea monosperma) are preferred by majority of the farmers due to the excellent growth and Lac secreted by the insects on them. The species are vulnerable to attack from moths like Eublemma roseonivia and Holcocera pulverea, and wasps like Coccophagus tschirchii and Tachardiaephagus tachardiae. India produces about 20000 tons of Lac annually from this species, hence is of great economic value to the farmers. This insect is known to reproduce sexually9.

\section{Paratachardina decorella:-}

This insect species on the rosette lac scale also belongs to the family 'Kerridae' and suborder 'Sternorrhyncha', as their mouth parts are in the rear position relative to their head. They are also isolately distributed around the Lac cultivation area, as their Lac production proficiency is not comparable to Kerria lacca?.

\section{Paratachardina pseudolobata:-}

It is a pestiferous and polyphagous lobate Lac scale insect. It is known to damage the host trees and is not found in India, though until 2007 A.D. it was mistakenly classified as Paratachardina decorella. This lobate Lac scale insect is able to grow on a number of plants and reproduces parthenogenetically in contrast to Kerria lacca which reproduces sexually ${ }^{\mathbf{1 0}}$.

\section{Socio-Economic Value of Lac Cultivation in Asia:-}

Lac cultivation in India is mainly confined to the states of Jharkhand whose contribution amounts to 57\%, followed by Madhya Pradesh to be 24\%, and the rest 19\% shared by Maharashtra, Orissa and West Bengal. This cultivation has proved to be a subsidiary source of income for the tribals ${ }^{3}$. The Indian Lac insect Kerria lacca mainly thrives on the succulent shoots of the plants Kusum, Pals and Ber, with other regional host trees also ${ }^{13,17}$. The Indian strains of Kerria lacca lac insect are Kusmi and Rangeeni, both having a life span of six months. The Kusumi strain of the insect generally thrives on Kusum tree accounting for almost 15\% of Lac production in India. The Rangeeni strain thrives on both Palas and Ber trees, accounting for almost $70 \%$ of the annual Lac yield ${ }^{\mathbf{1 1}}$.

The socio-economic condition of the Indian cultivators is dependent on their tree holdings. The holding of Palas tree was the highest to the extent of $88 \%$ amongst the cultivators followed by Ber and Palas to be $9 \%$ and $3 \%$ respectively ${ }^{3}$. The utilization of the host trees is also dependent on the number of trees and their growth, of each of the three species available for the Lac insect. Palas trees are available in large numbers, but they are not fully utilized for cultivation due to the poor economic conditions of the tribal natives. Still Palas is the largest source of income for the tribal communities ranging from INR 4 to 5 Lakh per Hectare of cultivation as the average price the cultivator received three years back was INR $75 / \mathrm{Kg}$ accounting for almost $85 \%$ share in consumer price ${ }^{8}$.

Lac cultivation itself, in the older times required a minimum investment in form of cultivation implements as the growth is on the host trees. Only labor was the economic factor to be taken care of. This led to hindrance in the output growth, which ultimately led to poor economic welfare of the tribal communities involved. Pest infestation 
also hampered the Lac insect growth. So, recent trend is towards implementation of some mechanization measures during cultivation stage like:

1. Purchase of seed (brood)

2. Pruning of the trees

3. Inoculation of the Lac insects on the host

4. Broodlac collection

5. Pest control measures

6. Lac harvesting and scraping

Labor variables and interest on working capital are also to be taken care of by the cultivator. The average production cost per tree is in the range of INR 1170/-. Broodlac can only be stored for a week. So purchase of fresh broodlac for inoculation is always costly for the farmers. Hence, many farmers retain a certain amount of their crop for rebrooding, thus saving their seed purchase cost. Sticklacs are prone to weight loss on storage amounting to as high as $30 \%$, so the farmers try to sell their output as early as possible after their collection. Moreover, this is weight loss factor is also applicable during inoculation of new crop; so a fine balance is to be maintained in order to curtail this economic loss as far as possible ${ }^{6}$. This also prevents the individual cultivator to infest all the trees available to him as his stock of brood is fixed. The cultivators generally form a group so that the risk factors as mentioned earlier are maintained to a minimum, and the group can help out each other in case of need right from infestation to harvesting.

\section{Importance of Lac Cultivation for Conservation of Biodiversity:-}

Lac cultivation is an important source of livelihood to tribal communities, as even in case of seasonal crop failure due to erratic monsoon conditions, Lac farming provided a sure source of income. Over and above that, Lac insects also play a prominent role in the conservation of biodiversity. Lac insects are able to thrive on a wide range of ecosystem. The Lac eco-system is a complex multi-trophic web of flora and fauna. Though Lac insects are preferably harvested on Ber, Kusum and Palas; but they are able to grow quite well on more than 400 species of trees ${ }^{\mathbf{1 3}, 15,17}$. This leads to the maintenance of diverse variety of plants having varied medicinal, economic and social significance. The richness of biodiversity involved in this farming can be judged from the abundance of 22 species of Lac predators with some 30 and 45 species of primary and secondary parasites, accompanied with many fungi, all surviving together without any clash. Lac farming also helps in the maintenance of other trees which are not directly involved in insect cultivation, thus increasing the diversity of the tree fauna on one hand, and proliferation of soil microorganisms on the other.

The Indian species of Paratachardina produce a hard and horny material which is insoluble in alcohol. As they are uni-voltine, meaning having one brood of generation in a year, they were considered as parasites in case of farming economically important commodities like tea and sandalwood ${ }^{\mathbf{1 5}}$. But recent research has shown that this Paratachardina species plays a vital role in bio-suppression of weed growth without the application of any pesticides ${ }^{1}$.

The commonly observed Indian strain Kerria lacca also plays an important role in maintaining biodiversity. Kerria lacca is further divided into two sub-strains: Kusumi and Rangeeni on the basis of their host preference, life cycle and the quality of Lac secreted. The Kusumi strain, as its name suggests, specifically prefers Kusum as the host tree and its life cycle is bi-voltine: two generations equal duration in a year, with a superior quality of resin that is produced. In case of Rangeeni, their life cycle is uni-voltine, with a lower grade of resin produced. Dyes obtained from Lac insects are not toxic, hence they are also incorporated in the manufacture of skin creams, food and drug manufacturing. A vast variation has been observed in inter-specific and intra-specific Lac hosts against the density of growth of Lac insects colonies, coupled with other factors like insect sex, size and mortality ${ }^{7,16}$.

\section{Interaction of Lac Insects with Surrounding Fauna:-}

The resin secretion of the insect serves to offer protection from adverse environmental conditions. But in spite of this due to the natural immobile characteristic of the insect, predators are able to attack and kill the insects very easily. There are some pathogenic fungi, 20 predators and some 75 parasites to which the Lac insect is prone to ${ }^{2}$. Lac hosts also sometimes known to destroy the insects ${ }^{12,14}$.

Impact on Biodiversity due to Decline in Lac Cultivation:-

Lac cultivation has been on the decline with the advent of synthetic drugs and dyes. This is also due to escalation of production costs compared to the economic returns. This has led to erosion in areas of Lac cultivation. The Lac host 
trees have been easily fallen prey to timber produce industries, as well as being used for fuel by the tribal people. This has led to the decline of other flora and fauna which rely on the host trees for their survival. Other plants of medicinal value are on the decline due to the destruction of the Lac host trees. Quick shrinkage observed in Lac cultivation is a serious threat to the overall biodiversity of the environment. The future of the Lac insects thus declines still further as their host trees become scarce. Intervention of scientific community is the need of the day to save the Lac insects from becoming extinct.

Lac insects have been observed to affect and are pests for some important produce like Mango, Sandal wood and Litchi. Pesticides are used to control the growth of Lac insects by these farmers. Elimination of Lac insects also leads to simultaneous erosion of the accompanying other flora and fauna. Research has shown that elimination of a single species of Lac insects has led to destruction of many other interrelated species of flora and fauna. Destruction of host trees like Ber has been detrimental to the survival of Lac insects. This has been especially observed in some states of India where Ber has made way for high yield fruit plantations. Cattle also prefer twigs of Lac host trees as their food, which leads to their decline on a longer scale. It is very difficult to revive once abandoned Lac cultivation, as the broodlac cannot be stored for more than seven days. Hence the availability of broodlac is also scarce coupled with the low growth rate of Lac culture. Lac seed germplasm banks need to be established to counter this problem ${ }^{15}$.

\section{Conclusion:-}

Preservation of Lac farming is the need of the day in order to preserve environmental biodiversity. This can be archived by integration of Lac farming with agricultural produce by conducting agricultural programs and educating the local populace of the benefits of Lac farming as its increased productivity will diversify the land use on one hand and save other associated flora and fauna from annihilation. Those species of Lac like Paratachardina species which yield Lac of low commercial value need to be subjected to modifications in their germplasm by research institutes. Development of a strong library covering all aspects of Lac growth, production and processing, development with economic viability is the need of the day for ultimate conservation of biodiversity.

\section{References:-}

1. Campbell MH, Holtcamp RH, McCormick LH, Wykes PJ, Donaldson JF, Gullan PJ, Gillespie PS (1994); Biological control of native shrubs, Cassina spp. using native scale insects, Austrotachardia and Paratachardina sp. (Hemipptera: Kerriidae) in New South Wales; Plant Prot. Q., 9: 64-68.

2. Das BB (1990); Present status of antomological research on lac in India and future strategies, Part I; Present status of Knowledge; Indian Shellac, (Annual No.): 9-16.

3. Jaiswal AK, Sharma KK, Kumar KK (2006); Importance of lac in the socio-economic life of tribals in Ranchi district (Jharkhand); New Agriculturist, 17(1,2); 133-137.

4. Kerria lacca: Wikipedia, The free encyclopedia

5. Lac: Wikipedia, The free encyclopedia

6. Mandal JP, Sarkhel J (2014); Cost of Lac cultivation and its profitability in Purulia district - A case study; Business Spectrum, IV(1): 1-10.

7. Mishra YD, Sushil SN, Bhattacharya A, Kumar S, Mallick A, Sharma KK (1999); Intraspecific variation in host plants affecting productivity of Indian lac insect, Kerria lacca (kerr); J Non Timber For Prod., 6: 114-117.

8. Pal G, Patel B (2013); An economic analysis of lac marketing in Kanker district of Chhattisgarh; The Indian Forester, 139(3): 256-259.

9. Paratachardina decorella: Wikipedia, The free encyclopedia

10. Paratachardina pseudolobata: Wikipedia, The free encyclopedia

11. Saka SK, Bhardwaj SP (1986); Lac cultivation a socio-economic study; Indian Shellac, Calcutta, 1\&2: 3-6.

12. Shaoji Gu (1993); An investigation on the pathogens of both lac insects and their host plants; For. Res., 6: 711-713.

13. Sharma K, Krishan, Ramani R, Mishra YD (1997); An additional list of the host plants of lac insects, Kerria spp. (Tachardiidae: Homoptera); Jr of Non-Timber Forest Products, 4(3, 4): 151-155.

14. Sharma KK, Jaiswal AK, Kumar KK (2001); New record of fungi associated with Indian lac insect Kerria lacca; Indian J of Entomol., 63: 369-371.

15. Sharma KK, Jaiswal AK, Kumar KK (2006); Role of lac culture in biodiversity conservation: Issues at stake and conservation strategy; Current Science, 91(7): 894-898.

16. Srinivasan MM (1956); Lac, its cultivation and manufacture in India. Ch. IV - Host plants of the lac insect; Ind For., 82: 182-193.

17. Varshney RK, Teotia TPS (1967); A supplementary list of host plants of lac insects; Jr Bombay Nat Hist Soc, 64(3): 488-511. 